\title{
A cyclosporin A/maltosyl- $\alpha$-cyclodextrin complex for inhalation therapy of asthma
}

\author{
H. Fukaya*,\#, A. limura*, K. Hoshiko*, T. Fuyumuro", S. Noji ${ }^{\Uparrow}$, T. Nabeshima
}

A cyclosporin Almaltosyl- $\alpha$-cyclodextrin complex for inhalation therapy of asthma. H. Fukaya, A. Iimura, K. Hoshiko, T. Fuyumuro, S. Noji, T. Nabeshima. (C) ES Journals Ltd 2003.

ABSTRACT: The inhalation of cyclosporin (Cs)A to the lung is limited by its hydrophobic properties. In order to improve the poor solubility of CsA, cyclodextrin (CD) was evaluated for its suitability for dry powder inhaler formation, and the benefit of an inhaled CsA/CD complex in vivo was demonstrated.

The solubilising effect of CDs on CsA was measured by high-performance liquid chromatography. Ciliostatic activity and haemolysis were determined to assess some safety profiles of CDs. The efficacy of an inhaled CsA/CD complex was evaluated by eosinophil infiltration into the bronchoalveolar lavage fluid in actively sensitised mice.

CDs markedly improved the poor solubility of CsA. The ciliostatic and haemolytic activities of maltosyl- $\alpha-C D$ were the weakest of all the tested CDs. CsA inhaled alone showed inhibitory effects on allergen-induced eosinophilia. Inhalation of the complex of CsA with maltosyl- $\alpha-C D$, where the dose of CsA was approximately nine-times less than that of CsA inhaled alone, also inhibited eosinophil accumulation significantly, with a longer duration of action in comparison with the response to CsA alone.

Thus the effective dose of cyclosporin A could be reduced by formation of a complex with maltosyl- $\alpha$-cyclodextrin, and a wider therapeutic safety margin by inhalation of cyclosporin A as a complex with maltosyl- $\alpha$-cyclodextrin could be expected.

Eur Respir J 2003; 22: 213-219.
*Discovery Biology Unit in Research Division and Pharmaceutical R\&D Group in Preclinical Development Dept, Novartis Pharma K.K. Research Institute, Tsukuba, and ${ }^{\#}$ Dept of Neuropsychopharmacology and Hospital Pharmacy, Nagoya University Graduate School of Medicine, Nagoya, Japan.

Correspondence: H. Fukaya, Discovery Biology Unit in Research Division, Novartis Pharma K.K. Research Institute, Tsukuba 300-2611, Japan.

Fax: 81298652385

E-mail: hiroaki.fukaya@pharma.novartis.com

Keywords: Asthma

cyclosporin A

eosinophil

inhalation therapy

maltosyl- $\alpha$-cyclodextrin

mice airway

Received: March 42002

Accepted after revision: April 142003
Cyclosporin (Cs)A has been shown to provide a clinical benefit in patients with chronic severe steroid-dependent asthma [1]. However, the oral medication of asthmatic patients with CsA is limited because of systemic side-effects [1]. In order to avoid this risk, the direct administration of CsA to the lung has been investigated in animals [2]. Generally, nebulisation of a liquid formulation of CsA has been used for the inhalation of CsA [3]. The liquid formulations of CsA aerosol for delivery to the lung are solutions of the drug that contain organic solvents and surfactants, such as ethanol, polyethylene glycol, propylene glycol or Cremophor EL [3]. Although the nebulising CsA solution for an intravenous application containing ethanol and caster oil as the vehicle is able to attenuate eosinophil and lymphocyte infiltration into the airway lumen, neutrophilia in the bronchoalveolar lavage (BAL) fluid is induced by the irritant properties of the ingredients of commercial products, such as castor oil or ethanol in ovalbumin (OA)-sensitised rats [2]. Therefore, the liquid formulation of $\mathrm{CsA}$ aerosol is limited due to its local irritant potency.

Micronised dry powder is another potential pharmaceutical form for the direct administration of compounds to the lung. It has been shown that inhalation of CsA dry powder is effective in inhibiting eosinophilia as an asthmatic model in guinea-pigs [4]. However, the direct exposure of CsA dry powder to the lung is limited due to its hydrophobic properties. Any drug delivered to the lung should be hydrophilic to dissolve in the mucous layer, and lipophilic to be absorbed through the cell membranes. In order to increase the absorption of CsA in the aqueous mucous layer, it would be necessary to increase the solubility of CsA in water. Cyclodextrins (CDs) are known to form inclusion complexes with lipophilic drugs as guest molecules and thus improve their water solubility. Furthermore the important characteristics of CDs are that they form inclusion complexes both in solution and in the solid state [5]. There are reports showing the improvement of pharmaceutical properties of CsA using formation of complexes with $\mathrm{CD} ; \alpha-\mathrm{CD}$ improves the solubility of CsA in ophthalmic solutions [6], dimethyl (DM)- $\alpha-C D$ forms a complex with CsA and improves the oral absorption of CsA in rats [7], and CsA complexed with DM- $\beta-C D$ results in increased solubility [8] and dissolution rate of CsA in the gastrointestinal tract [9]. Two reports exist regarding the application of $\mathrm{CD}$ as a drug carrier in aerosols $[10,11]$. Thus, it was hypothesised that $\mathrm{CD}$ acts as a carrier agent and transports CsA through an aqueous milieu to the lipophilic absorption site of membranes. Moreover, when inhaled, the CsA/CD complex is expected to reduce the effective dose required to inhibit inflammatory cell accumulation compared with CsA inhaled alone. Consequently, the CsA/CD complex would be expected to have a wider therapeutic margin. In addition, the toxicity of CDs may be of concern.

In this study, four kinds of CDs were evaluated for their suitability for dry powder inhalation. In order to determine the antiasthmatic action of $\mathrm{CsA} / \mathrm{CD}$ complex, it was evaluated by allergen-induced eosinophil accumulation in the airways in OA-sensitised mice under inhalant application. 


\section{Materials and methods}

\section{Chemicals}

CsA was from Novartis AG (Basel, Switzerland). $\alpha-C D$ and DM- $\beta-C D$ were from Nihon Shokuhin Kako (Tokyo, Japan). Glucosyl- $\alpha-C D(G 1-\alpha-C D)$ and maltosyl- $\alpha-C D$ (G2$\alpha-C D)$ were from Bio Research Corporation of Yokohama (Yokohama, Japan). OA (grade V) was from Sigma (St Louis, MO, USA). Inactivated Bordetella pertussis vaccine was from Wako Pure Chemicals (Osaka, Japan). Intal@ was from Fujisawa Pharmaceutical (Osaka, Japan).

The micronised dry powder for pharmacological study was prepared as follows. CsA, G2- $\alpha-\mathrm{CD}$, and a mixture of these compounds were kneaded for $3 \mathrm{~h}$ with gradual addition of purified water. The kneaded samples were dried for $24 \mathrm{~h}$ under the condition of reduced pressure followed by preliminary drying for $2 \mathrm{~h}$ at $40^{\circ} \mathrm{C}$. To make the micronised dry powder, the samples were pulverised by a Jet Mill (Powrex Corporation, Hyogo, Japan), and further drying was carried out under reduced pressure. The particle size of the products were: micronised dry powder of CsA (Lot 971205) $2.47 \mu \mathrm{m}$, micronised dry powder of CsA/G2- $\alpha$-CD complex (Lot 980728) $3.15 \mu \mathrm{m}$, and micronised dry powder of G2- $\alpha-\mathrm{CD}$ (Lot 980820) $2.76 \mu \mathrm{m}$. These particle sizes were measured using a particle size analyser (Aerosizer; API, Boston, MA, USA).

\section{Animals}

Bull frogs (Saitama-Jikkenn-Dohbutu, Saitama, Japan) were used as the source of cilia. For the BAL assessment, male BALB/c mice (22-31 g body weight; Charles River, Tokyo, Japan) were used. Mice received water and food $a d$ libitum. All animal experiments were approved by the Novartis Pharma K.K. Tsukuba Research Institute Animal Experimentation Ethics Committee and performed according to the Guideline for Animal Experimentation approved by the Japanese Association for Laboratory Animal Science, 1987.

\section{Solubilising ability for cyclosporin A}

To evaluate the solubilising ability of CDs, a surplus amount of CsA was added into a saturated solution of various CDs. From the preliminary observation where the saturation point of $\mathrm{CDs}$ in water at $20^{\circ} \mathrm{C}$ was measured in the separated experiments, the concentration at $10 \%(\mathrm{w} / \mathrm{v})$ for $\alpha-C D, 57 \%(w / v)$ for DM- $\beta-C D, 40 \%(w / v)$ for $G 1-\alpha-C D$ and G2- $\alpha-C D$ were chosen. The mixture solutions of CsA and $\mathrm{CDs}$ were stirred and incubated for $3 \mathrm{~h}$ at $20^{\circ} \mathrm{C}$, and then the concentrations of CsA in the saturated solution were measured by high-performance liquid chromatography (HPLC) with ultraviolet (UV) detection (LC6A system; Shimadzu, Kyoto, Japan). The HPLC conditions were as follows: detector UV at $214 \mathrm{~nm}$; column LiChospher 100, RP-8(e) (Merck, Darmstadt, Germany) heated at $70^{\circ} \mathrm{C}$; mobile phase acetonitrile/water/methanol/phosphoric acid $=12 / 7 / 1 / 0.001(\mathrm{v} / \mathrm{v})$; flow rate $2.0 \mathrm{~mL} \cdot \mathrm{min}^{-1}$; and injection volume $20 \mu \mathrm{L}$.

\section{Measurement of ciliostatic potential}

In order to assess the safety property to mucosa, the ciliostatic potential was observed. The cilia preparation was isolated from the upper palate of frogs. The preparation kept the mucociliated epithelium of the frog palate functionally intact but was thin enough for light to be transmitted. The isolated cilia were perfused in $0.6 \%(\mathrm{w} / \mathrm{v}) \mathrm{NaCl}$ solution (the physiological saline for frogs), and each solution of CDs, Intal $\mathbb{R}$ and inclusion complex of CsA with $G 2-\alpha-C D$. All chemicals were dissolved in distilled water. In order to assess the cilio-inhibition of CDs alone, the concentrations of all CDs were adjusted to $10 \%$ as the saturated concentration of $\alpha-C D$. The safety property of the experimental formulation of CsA/G2- $\alpha$-CD complex in comparison with that of Intal $\mathbb{R}$ on ciliary movement was evaluated. In this experiment, $5 \%$

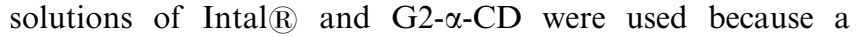
relatively high viscosity $(11.02 \mathrm{mPa} \times \mathrm{s})$ of $10 \%$ Intal $\mathbb{R}$ solution, measured by a rotation viscosimeter (model RB100L; Tohki Sangyo, Tokyo, Japan), was observed. While at the concentration of $5 \%$, the viscosities of all sample were observed in the range of $1.10-1.13 \mathrm{mPa} \times \mathrm{s}$. The duration of ciliary beat movement was measured microscopically for a maximum of $60 \mathrm{~min}$. The osmotic pressure of each sample solution was measured by an osmometer (model 3MO; Advance Instruments, Tokyo, Japan).

\section{Haemolytic property of cyclodextrins}

Haemolytic properties were examined to assess the cytotoxicity of CDs. CDs were dissolved with phosphate-buffered saline (PBS), at pH 7.4 as the sample solution. Pooled rabbit blood (Oriental Bio-Service, Tsukuba, Japan) was diluted to $1 \%(\mathrm{v} / \mathrm{v})$ with PBS as $0 \%$ haemolysis, sample solutions of CDs at several concentrations, and phosphate-buffered $1 \% \mathrm{NaCl}$ solution as $100 \%$ haemolysis. All solutions were then incubated for $30 \mathrm{~min}$ at $37^{\circ} \mathrm{C}$. After incubation, sample tubes were centrifuged at $1500 \times g$ for $5 \mathrm{~min}$ at room temperature. The supernatant was transferred into the cubette and the absorbance was measured for haemoglobin at $540 \mathrm{~nm}$ using a UV spectrophotometer. The degree of haemolysis was calculated as the percentage of haemoglobin released from the total, caused by phosphate-buffered $1 \% \mathrm{NaCl}$ solution.

\section{Sensitisation procedure}

The mice received $10 \mu \mathrm{g}$ OA mixed with $5 \mathrm{mg} \mathrm{Al}(\mathrm{OH})_{3}$ and 1 billion microorganisms of inactivated Bordetella pertussis vaccine in a volume of $0.5 \mathrm{~mL}$ saline subcutaneously on day 1. This procedure was repeated on day 14 as a booster. On day 21, the animals were held in a nose-only inhalation chamber (Shibata, Tokyo, Japan) and exposed to $10 \mathrm{mg} \cdot \mathrm{mL}^{-1}$ OA for $1 \mathrm{~h}$.

\section{Drug administration}

The animals were held in a nose-only inhalation chamber and exposed to micronised $\mathrm{G} 2-\alpha-\mathrm{CD}$, micronised $\mathrm{CsA}$, or micronised CsA/G2- $\alpha-\mathrm{CD}$ complex containing 49.7\% CsA with a dust feeder (Shibata). Preliminarily, several exposure durations of the inhalation of CsA alone were examined. Significant inhibitory activity on eosinophil influx into airways was observed when CsA was inhaled for $60 \mathrm{~min}$ (1116.7 $5.9 \mu \mathrm{g} \cdot \mathrm{kg}^{-1}$ in the airways), but in the case of the shorter duration of exposure, i.e. for $10 \mathrm{~min}\left(186.0 \pm 0.7 \mu \mathrm{g} \cdot \mathrm{kg}^{-1}\right.$ in the airways) or $30 \mathrm{~min}\left(557.8 \pm 3.0 \mu \mathrm{g} \cdot \mathrm{kg}^{-1}\right.$ in the airways), the eosinophil influx was not inhibited (data not shown). Conversely, CsA/G2- $\alpha-C D$ was expected to be effective at a much lower concentration, and in the separate study using rats, it was $\sim 10$ times more effective than CsA inhaled alone (data not shown). Therefore, based on this, the duration of exposure of each micronised dry powder product was set as 
follows to control the whole-body inhaled doses: CsA for $60 \mathrm{~min}$, and $\mathrm{CsA} / \mathrm{G} 2-\alpha-\mathrm{CD}$ complex and $\mathrm{G} 2-\alpha-\mathrm{CD}$ for $10 \mathrm{~min}$. This dry powder inhalation was terminated $1,3,6,12$, 18 or $24 \mathrm{~h}$ prior to the OA challenge on day 21 . The experiments were made separately on each test compound.

\section{Determination of the concentration of the compounds in the chamber}

Air from the chamber was aspirated $\left(20 \mathrm{~L} \cdot \mathrm{min}^{-1}\right)$ through a paper filter using an air sampler (LD-20; Shibata). The filter was weighed before and after aspiration of a defined volume of aerosol and the concentration of the compounds in the chamber was calculated from these gravimetric measurements.

\section{Estimation of drug concentration in the animals}

The whole-body inhaled doses of the compounds were estimated according to the following formula:

Dose $\left(\mathrm{mg} \cdot \mathrm{kg}^{-1}\right)=$

$\frac{\text { Concentration in the chamber }\left(\mathrm{mg} \cdot \mathrm{L}^{-1}\right) \times \mathrm{RMV}\left(\mathrm{L} \cdot \mathrm{min}^{-1}\right) \times \mathrm{D}(\mathrm{min}) \times \mathrm{F}}{\mathrm{W}(\mathrm{kg})}$

where $\mathrm{D}$ is the duration of exposure to the compound, $\mathrm{F}$ is the proportion of inhalable particles $(\leqslant 5.4 \mu \mathrm{m})$, W is the body weight of the animals, and RMV is the rate of minute volume, which is equal to the volume of air inhaled in $1 \mathrm{~min}(4.19 \times$ $\left.\mathrm{W}(\mathrm{g})^{0.66} / 1000\right)$.

The value of RMV was calculated according to the report of MCMAHON et al. [12]. The amount of inhaled compound in the lung was assumed to be $5 \%$ of the estimated whole-body dose [13].

Assessment of the particle size of the compound in the chamber

Air from the animal chamber was aspirated by a pump $\left(2 \mathrm{~L} \cdot \mathrm{min}^{-1}\right)$ and directed to a particle size analyser (Aerosizer; API). Geometric particle size values were used throughout the study. The population of $\leqslant 5.4 \mu \mathrm{m}$ particle sizes was used to calculate the inhaled doses as the "F value" in the above formula.

\section{Bronchoalveolar lavage}

The animals were sacrificed by an intraperitoneal injection of an overdose of pentobarbital (Dinabbott, Tokyo, Japan) $48 \mathrm{~h}$ after the allergen challenge. When respiration was no longer evident, the trachea was exposed and cannulated. The lung tissues were washed with three aliquots $(1 \mathrm{~mL})$ of $\mathrm{Ca}^{2+}$ - and $\mathrm{Mg}^{2+}$-free Hank's balanced salt solution (HBSS; Gibco Life Technologies Ltd, Paisley, UK) containing $10 \mathrm{mM}$ ethyldiamine tetraacetic acid (Kanto, Japan) and $1 \mathrm{mM} \mathrm{N}$-2hydroxyethylpiperazine- $N$-2-ethanesulphonic acid (HEPES) buffer (Gibco Life Technologies Ltd), and $\mathrm{pH}$ was adjusted to 7.4 (modified HBSS), warmed at $37^{\circ} \mathrm{C}$. Fluid recovery from the three washes exceeded $>90 \%$. Lavage fluid was centrifuged $\left(200 \times g\right.$ at $4^{\circ} \mathrm{C}$ for $\left.10 \mathrm{~min}\right)$, and the cell pellet was resuspended in $0.5 \mathrm{~mL}$ of modified HBSS, and total cell numbers were determined using a cell counter (F-300; Toa, Tokyo, Japan). In order to differentiate cell types, smears were prepared with a cytocentrifuge (Cytospin 3; Shandon, Runcorn, UK). Smears were stained with May-Grünwald and Giemsa dye solution (Diff-Quick; Midorijuji, Osaka, Japan). At least 500 cells from each smear were counted under a light microscope. The proportion of each cell population was expressed as a percentage of total cells and this ratio together with the total cell count was used to calculate the number of each cell type.

\section{Data analysis}

All data are expressed as a mean \pm SEM. An unpaired t-test was used to assess the statistical significance of the difference between the untreated no OA-challenged group and untreated OA-challenged group. When a significant difference was observed by an $\mathrm{F}$ test to compare variances, an unpaired t-test with Welch's correction was used. Bonferroni's multiple comparison test was used to assess the statistical significance of the difference between the control and drug-treated groups in OA-challenged mice after a one-way analysis of variance; a $\mathrm{p}<0.05$ was considered significant.

\section{Results}

\section{Solubility}

The solubility of CsA was improved by formation of complexes with CDs tested in this study. The solubility of CsA increased $\sim 40,570,130$ and 80-fold in the presence of $\alpha-\mathrm{CD}, \mathrm{DM}-\beta-\mathrm{CD}, \mathrm{G} 1-\alpha-\mathrm{CD}$ and G2- $\alpha-\mathrm{CD}$, respectively (table 1).

\section{Ciliostatic and haemolytic potential of cyclodextrins}

The frog palate has been widely used as a model to investigate the properties of the respiratory tract mucociliary apparatus [14-17]. Therefore, in order to assess the cilioinhibition of CDs, the effects of CDs on ciliary beat movement of the isolated frog upper palate was determined. The degree of increase in ciliostatic potential was dependent on the kind of CDs, in the order G2- $\alpha-\mathrm{CD}<\mathrm{G} 1-\alpha-\mathrm{CD}<\mathrm{DM}-\beta-$ $\mathrm{CD}<\alpha-\mathrm{CD}$ at a concentration of $10 \%$ (table 2). Osmotic pressures of all compound solutions tested in this experiment were comparable to that of $0.6 \% \mathrm{NaCl}$ solution. Therefore, osmolarity may not contribute to the effects on ciliary beat movement.

The haemolytic potentials of CDs were also assessed. G2- $\alpha-$ $\mathrm{CD}$ did not enhance haemolysis at concentrations up to $2 \%$. In contrast $\alpha-C D, D M-\beta-C D$ and G1- $\alpha-C D$ markedly increased haemolysis in a concentration-dependent manner (fig. 1).

These data indicate that $\mathrm{G} 2-\alpha-\mathrm{CD}$ was the most promising candidate on the basis of solubility, cilio-inhibition and haemolytic properties. To evaluate the safety property of the experimental formulation of $\mathrm{CsA} / \mathrm{G} 2-\alpha-\mathrm{CD}$ complex on ciliary movement, the ciliostatic effect of CsA-saturated G2- $\alpha-C D$ solution was compared, at the concentration of $5 \%$, with that of a solution of G2- $\alpha-C D$ alone or the content of Intal

Table 1.-Solubility of cyclosporin (Cs)A in the presence of cyclodextrin (CD)

\begin{tabular}{lccc}
\hline CD & $\begin{array}{c}\text { CD } \\
\text { concentration }^{\#} \%\end{array}$ & $\begin{array}{c}\text { Solubility } \\
\text { of CsA mM }\end{array}$ & $\begin{array}{c}\text { Solubility } \\
\text { ratio }\end{array}$ \\
\hline$\alpha-C D$ & 10 & 1.57 & 39 \\
DM- $\beta-C D$ & 57 & 22.86 & 572 \\
G1- $\alpha$-CD & 40 & 5.11 & 128 \\
G2- $\alpha$-CD & 40 & 3.11 & 78 \\
\hline
\end{tabular}

\#: concentration of CDs in water. At these concentrations, each CDs was nearly saturated in water at $20^{\circ} \mathrm{C}$. ${ }^{\text {? }}$ : the ratio of the solubility of $\mathrm{CsA}$ in water at $20^{\circ} \mathrm{C}(0.04 \mathrm{mM})$. 
Table 2. - The ciliostatic potential of cyclodextrins (CDs): effects of cyclosporin (Cs)A-saturated CD solution and Intal $\mathbb{R}$ solution on ciliary beat movement of the isolated preparation from frog upper palate

\begin{tabular}{|c|c|c|}
\hline $\begin{array}{l}\text { Sample } \\
\text { solution }\end{array}$ & $\begin{array}{l}\text { Duration of ciliary } \\
\text { beat movement min }\end{array}$ & $\begin{array}{c}\text { Osmotic } \\
\text { pressure mOsm }\end{array}$ \\
\hline $0.6 \% \mathrm{NaCl}$ & $>60$ & 190 \\
\hline $10 \% \alpha-C D$ & $1.9 \pm 0.2$ & 196 \\
\hline $10 \%$ DM- $\beta-C D$ & $4.7 \pm 0.8$ & 197 \\
\hline $10 \% \mathrm{G} 1-\alpha-\mathrm{CD}$ & $11.6 \pm 2.8$ & 200 \\
\hline $10 \% \mathrm{G} 2-\alpha-\mathrm{CD}$ & $15.5 \pm 3.2$ & 198 \\
\hline $5 \% \mathrm{G} 2-\alpha-\mathrm{CD}$ & $17.4 \pm 2.3$ & 194 \\
\hline $\mathrm{CsA} / \mathrm{G} 2-\alpha-\mathrm{CD}^{\#}$ & $21.0 \pm 2.7$ & 194 \\
\hline $5 \%$ Intal@ & $14.6 \pm 2.6$ & 172 \\
\hline
\end{tabular}

Data are presented as mean \pm SEM. ${ }^{*}$ : CsA was saturated in $5 \% \mathrm{G} 2-\alpha-$ $\mathrm{CD}$ solution. The concentration of CsA in the saturated solution was $94.7 \mu \mathrm{g} \cdot \mathrm{mL}^{-1}$.

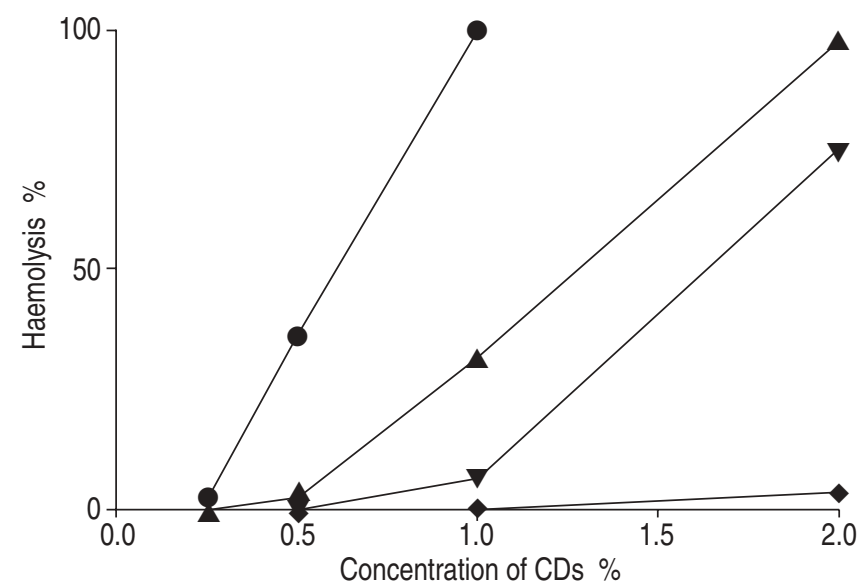

Fig. 1.-Haemolysis potential of $\alpha$-cyclodextrin (CD; $\boldsymbol{\Delta})$, glucosyl- $\alpha$ $\mathrm{CD}(\boldsymbol{\nabla})$, maltosyl- $\alpha-\mathrm{CD}(\bullet)$ and dimethyl- $\beta-\mathrm{CD}(\boldsymbol{\bullet})$.

Capsule $\mathbb{R}$, which is a dry powder inhalation product on the market in Japan. Similar duration of ciliary beat movement was observed when these three solutions were perfused (table 2). Thus, it could be argued that the cilio-inhibition properties of CsA-saturated G2- $\alpha-\mathrm{CD}$ and G2- $\alpha-\mathrm{CD}$ were very comparable to those of Intal Capsule $\mathbb{R}$.

\section{Inflammatory cell influx into the airways following allergen exposure}

The exposed doses of inhaled micronised dry powder products to mice were calculated according to the above methods. From the calculation, the dose of CsA in the airways of actively sensitised mice after the inhalation of CsA and CsA/G2- $\alpha-C D$ complex were estimated to be $1325.5 \pm$ $21.7 \mu \mathrm{g} \cdot \mathrm{kg}^{-1}$ and $153.9 \pm 2.3 \mu \mathrm{g} \cdot \mathrm{kg}^{-1}$, respectively (table 3 ).

Inhalation of CsA alone significantly inhibited allergeninduced eosinophil influx into the airways of actively sensitised mice in a time-dependent manner (fig. 2).

The efficacy of CsA alone disappeared when it was treated 18 and $24 \mathrm{~h}$ prior to allergen exposure. Thus, the onset of action of CsA inhaled alone on allergen-induced eosinophil influx was within $1-3 \mathrm{~h}$ and the duration of action was $<18 \mathrm{~h}$ in this model. The inhalation of $\mathrm{CsA} / \mathrm{G} 2-\alpha-\mathrm{CD}$ complex, where the dose of CsA in airways was approximately ninetimes less than that of CsA alone (table 3), also showed an apparent effect on eosinophil influx into the airways (fig. 3).
Table 3. - The exposed doses of inhaled micronised dry powder products and estimated doses of cyclosporin (Cs)A after the inhalation of CsA alone and CsA/maltosyl- $\alpha$-cyclodextrin (G2- $\alpha$ $\mathrm{CD})$ complex in the airway of actively sensitised mice

\begin{tabular}{lccc}
$\begin{array}{l}\text { Micronised } \\
\text { dry powder } \\
\text { products }\end{array}$ & $\begin{array}{c}\text { Whole-body } \\
\text { dose } \\
\mathrm{mg} \cdot \mathrm{kg}^{-1}\end{array}$ & $\begin{array}{c}\text { Exposed dose } \\
\text { in the airways } \\
\mu \mathrm{g} \cdot \mathrm{kg}^{-1}\end{array}$ & $\begin{array}{c}\text { Estimated dose } \\
\text { of CsA in the } \\
\text { airways } \mu \mathrm{g} \cdot \mathrm{kg}^{-1}\end{array}$ \\
\hline $\mathrm{CsA}^{\#}$ & $26.5 \pm 0.4$ & $1325.5 \pm 21.7$ & $1325.5 \pm 21.7$ \\
$\mathrm{CsA}^{\mathrm{G}} \mathrm{G} 2-\alpha-\mathrm{CD}$ & $6.2 \pm 0.1$ & $309.7 \pm 4.6$ & $153.9 \pm 2.3^{+}$ \\
$\mathrm{G} 2-\alpha-\mathrm{CD}^{\boldsymbol{9}}$ & $6.7 \pm 0.04$ & $334.6 \pm 2.2$ & \\
\hline
\end{tabular}

Data are presented as mean \pm SEM. The conditions used in the three different experiments shown in tables 4,5 and 6 are summarised in this table. ${ }^{\#}$ : micronised dry powder of CsA was inhaled by the mice for $60 \mathrm{~min}$ at the mean concentration in the chamber of $0.307 \mathrm{mg} \cdot \mathrm{L}^{-1}$; ?: micronised dry powder of CsA/G2- $\alpha-C D$ complex and G2- $\alpha-C D$ were inhaled by the mice for $10 \mathrm{~min}$ at the mean concentration in the chamber of $0.540 \mathrm{mg} \cdot \mathrm{L}^{-1}$ and $0.550 \mathrm{mg} \cdot \mathrm{L}^{-1}$, respectively; ${ }^{+}: \mathrm{CsA} / \mathrm{G} 2-\alpha-$ CD complex contains $49.7 \%$ (w/w) CsA.

A significant inhibitory effect on eosinophil influx was observed when CsA/G2- $\alpha-C D$ complex was inhaled at 12 and $18 \mathrm{~h}$ prior to allergen exposure. The onset of action of CsA/ G2- $\alpha-C D$ complex was slightly slower than that of CsA alone (fig. 3). In contrast with CsA inhaled alone, the significant inhibitory activity remained $18 \mathrm{~h}$ after the inhalation of CsA/ G2- $\alpha-C D$ complex. Neither CsA alone nor CsA/G2- $\alpha-C D$ showed any significant effects on the other inflammatory cells in the airways (tables 4 and 5). Furthermore, G2- $\alpha$-CD inhaled alone did not show any significant effects for the eosinophil influx into the airways. Although G2- $\alpha-\mathrm{CD}$ inhaled alone tended rather to increase the number of inflammatory cells into the airways, these changes were not significant in the statistical calculation (table 6).

\section{Discussion}

CsA has low oral bioavailability due to its poor solubility in aqueous solutions and large molecular weight. In the present study, the solubility of CsA was markedly improved by formation of inclusion complexes with $\alpha-C D, D M-\beta-C D, G 1-\alpha-C D$ and G2- $\alpha-C D$. The solubility of CsA increased 570 -fold in the

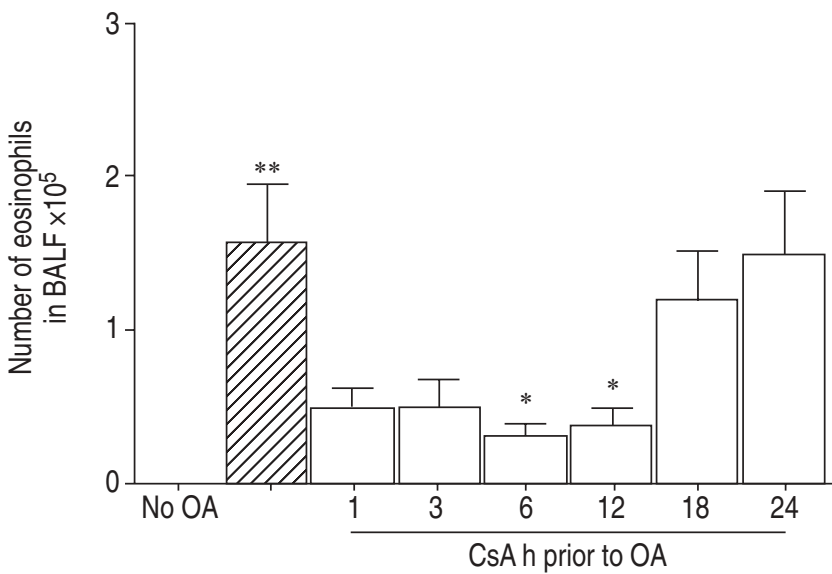

Fig. 2. - Time-course effect of inhaled cyclosporin (Cs)A (1325.5 $\mu \mathrm{g} \cdot \mathrm{kg}^{-1}$ in the airways) on allergen-induced eosinophil influx into the airways of actively sensitised mice $(n=6-8)$. BALF: bronchoalveolar lavage fluid. Ovalbumin (OA) challenge was equal to $10 \mathrm{mg} \cdot \mathrm{mL}^{-1}$. *: $\mathrm{p}<0.05$ in comparison with the response of the untreated OA-challenged group $(\mathbb{Z})$; $* *: \mathrm{p}<0.01$ in comparison with the response of the untreated no OA-challenged group (No OA). 


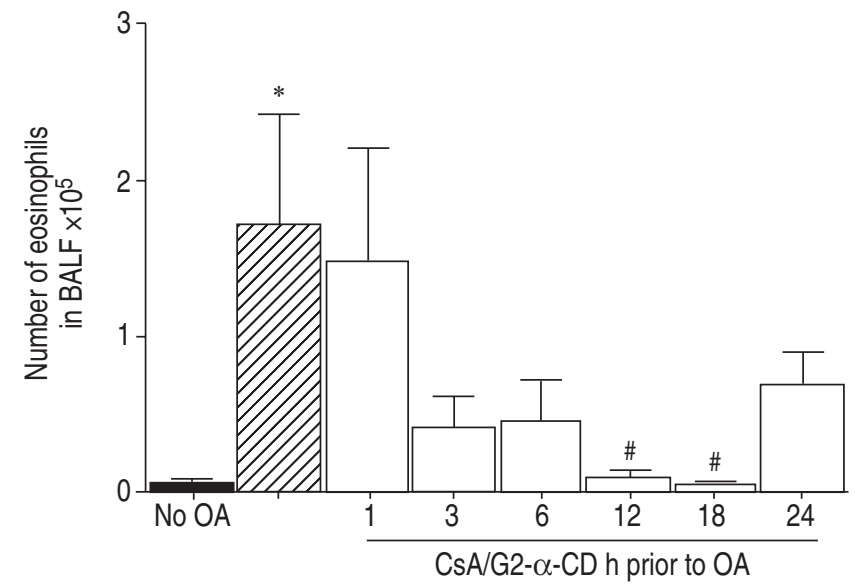

Fig. 3. - Time-course effect of inhaled cyclosporin (Cs)A/maltosyl- $\alpha$ cyclodextrin $(\mathrm{G} 2-\alpha-\mathrm{CD})$ complex $\left(309.7 \mu \mathrm{g} \cdot \mathrm{kg}^{-1}\right.$ in the airways; $153.9 \mu \mathrm{g} \cdot \mathrm{kg}^{-1}$ in the airways as CsA) on allergen-induced eosinophil influx into the airways of actively sensitised mice $(n=9-10)$. Ovalbumin (OA) challenge was equal to $10 \mathrm{mg} \cdot \mathrm{mL}^{-1}$. *: $\mathrm{p}<0.05$ in comparison with the response of the untreated no OA-challenged group ( $\mathbf{\square})$; \#: $\mathrm{p}<0.05$ in comparison with the response of the untreated OAchallenged group $(\mathbb{Z})$.

presence of $474 \mathrm{mM}$ DM- $\beta-C D$. DM- $\beta-C D$ has been widely used to improve the pharmaceutical characteristics of CsA $[8,9]$ and other drugs [11, 18-20]. Intranasal application of insulin inclusion complexes with DM- $\beta-C D$ greatly increase
Table 4.-Inflammatory cell infiltration after the inhalation of cyclosporin (Cs)A alone in the airways of actively sensitised mice

\begin{tabular}{|c|c|c|c|}
\hline \multirow[t]{2}{*}{ Group $^{\#}$} & \multicolumn{3}{|c|}{ Number of cells in BALF $\times 10^{5}$} \\
\hline & Macrophage & Eosinophil & Neutrophil \\
\hline No OA challenge & $6.6 \pm 0.7$ & $0 \pm 0$ & $0.1 \pm 0.0$ \\
\hline OA challenge & $6.4 \pm 0.9$ & $1.6 \pm 0.4^{* *}$ & $1.5 \pm 0.6^{*}$ \\
\hline \multicolumn{4}{|l|}{ OA challenged at } \\
\hline $1 \mathrm{~h}$ after $\mathrm{CsA}^{\tau}$ inhalation & $6.6 \pm 0.8$ & $0.5 \pm 0.1$ & $1.3 \pm 0.4$ \\
\hline $3 \mathrm{~h}$ after $\mathrm{CsA}^{\Uparrow}$ inhalation & $5.7 \pm 0.7$ & $0.5 \pm 0.2$ & $1.2 \pm 0.5$ \\
\hline $6 \mathrm{~h}$ after $\mathrm{CsA}^{\top}$ inhalation & $9.0 \pm 1.0$ & $0.3 \pm 0.1^{+}$ & $2.2 \pm 0.7$ \\
\hline $12 \mathrm{~h}$ after $\mathrm{CsA}^{\top}$ inhalation & $5.7 \pm 0.6$ & $0.4 \pm 0.1^{+}$ & $2.5 \pm 1.9$ \\
\hline $18 \mathrm{~h}$ after $\mathrm{CsA}^{\top}$ inhalation & $7.6 \pm 0.8$ & $1.2 \pm 0.3$ & $1.2 \pm 0.3$ \\
\hline $24 \mathrm{~h}$ after $\mathrm{CsA}^{\top}$ inhalation & $7.2 \pm 0.7$ & $1.5 \pm 0.4$ & $1.4 \pm 0.4$ \\
\hline
\end{tabular}

BALF: bronchoalveolar lavage fluid. ${ }^{*}: \mathrm{n}=6-8{ }^{\circ}$ : the exposed dose of CsA was calculated as $1325.5 \pm 21.7 \mu \mathrm{g} \cdot \mathrm{kg}^{-1}$ in the airways. ${ }^{*}: \mathrm{p}<0.05$; **: $\mathrm{p}<0.01$ in comparison with the response of the untreated no ovalbumin (OA)-challenged group; ${ }^{+}: \mathrm{p}<0.05$ in comparison with the response of the untreated OA-challenged group.

serum insulin concentration in rats compared with the dosage form in the absence of CD, and enhancement of the dissolution rate leads to improved biological efficacy of the complexed insulin [20]. However, in the report, DM- $\beta$-CD caused a moderate ciliostatic effect. The role of the cilia in the respiratory tract is exceedingly important for the natural defence mechanism against foreign agents. Inhaled drugs are

Table 5. - Inflammatory cell infiltration after the inhalation of cyclosporin (Cs)A/maltosyl- $\alpha$-cyclodextrin (G2- $\alpha$-CD) in the airways of actively sensitised mice

\begin{tabular}{|c|c|c|c|}
\hline \multirow[t]{2}{*}{ Group $^{\#}$} & \multicolumn{3}{|c|}{ Number of cells in BALF $\times 10^{5}$} \\
\hline & Macrophage & Eosinophil & Neutrophil \\
\hline No OA challenge & $5.8 \pm 0.7$ & $0.1 \pm 0.0$ & $0.01 \pm 0.00$ \\
\hline OA challenge & $6.6 \pm 0.8$ & $1.7 \pm 0.7^{*}$ & $1.4 \pm 0.7 *$ \\
\hline \multicolumn{4}{|l|}{ OA challenged at } \\
\hline $1 \mathrm{~h}$ after $\mathrm{CsA} / \mathrm{G} 2-\alpha-\mathrm{CD}^{-}$inhalation & $10.1 \pm 1.8$ & $1.5 \pm 0.7$ & $1.7 \pm 0.6$ \\
\hline $3 \mathrm{~h}$ after $\mathrm{CsA} / \mathrm{G} 2-\alpha-\mathrm{CD}$ inhalation & $7.5 \pm 1.2$ & $0.4 \pm 0.2$ & $1.0 \pm 0.9$ \\
\hline $6 \mathrm{~h}$ after $\mathrm{CsA} / \mathrm{G} 2-\alpha-\mathrm{CD}^{\top}$ inhalation & $7.0 \pm 2.1$ & $0.5 \pm 0.3$ & $0.7 \pm 0.3$ \\
\hline $12 \mathrm{~h}$ after $\mathrm{CsA} / \mathrm{G} 2-\alpha-\mathrm{CD}^{\top}$ inhalation & $6.4 \pm 0.7$ & $0.1 \pm 0.04^{+}$ & $0.1 \pm 0.1$ \\
\hline $18 \mathrm{~h}$ after $\mathrm{CsA} / \mathrm{G} 2-\alpha-\mathrm{CD}^{\top}$ inhalation & $6.1 \pm 0.9$ & $0.04 \pm 0.01^{+}$ & $0.02 \pm 0.01$ \\
\hline $24 \mathrm{~h}$ after $\mathrm{CsA} / \mathrm{G} 2-\alpha-\mathrm{CD}^{\top}$ inhalation & $5.7 \pm 0.4$ & $0.7 \pm 0.2$ & $0.3 \pm 0.1$ \\
\hline
\end{tabular}

BALF: bronchoalveolar lavage. ${ }^{\#}: \mathrm{n}=9-10$; ${ }^{\bullet}$ : the exposed dose of CsA was calculated as $153.9 \pm 2.3 \mu \mathrm{g} \cdot \mathrm{kg}^{-1}$ in the airways. *: p<0.05 in comparison with the response of the untreated no ovalbumin (OA)-challenged group; ${ }^{+}: \mathrm{p}<0.05$ in comparison with the response of the untreated OA-challenged group.

Table 6. - Inflammatory cell infiltration after the inhalation of maltosyl- $\alpha$-cyclodextrin (G2- $\alpha$-CD) alone in the airway of actively sensitised mice

\begin{tabular}{|c|c|c|c|}
\hline \multirow[t]{2}{*}{ Group $^{\#}$} & \multicolumn{3}{|c|}{ Number of cells in BALF $\times 10^{5}$} \\
\hline & Macrophage & Eosinophil & Neutrophil \\
\hline No OA challenge & $6.2 \pm 1.2$ & $0 \pm 0$ & $0 \pm 0$ \\
\hline OA challenge & $8.0 \pm 1.3$ & $0.7 \pm 0.2^{* *}$ & $1.3 \pm 0.5^{*}$ \\
\hline \multicolumn{4}{|l|}{ OA challenged at } \\
\hline $1 \mathrm{~h}$ after $\mathrm{G} 2-\alpha-\mathrm{CD}^{\top}$ inhalation & $13.6 \pm 3.2$ & $1.8 \pm 0.5$ & $3.7 \pm 1.6$ \\
\hline $3 \mathrm{~h}$ after $\mathrm{G} 2-\alpha-C D^{-}$inhalation & $9.5 \pm 2.2$ & $1.2 \pm 0.5$ & $1.6 \pm 0.7$ \\
\hline $6 \mathrm{~h}$ after $\mathrm{G} 2-\alpha-\mathrm{CD}^{\top}$ inhalation & $6.9 \pm 1.1$ & $0.8 \pm 0.1$ & $1.6 \pm 0.6$ \\
\hline $12 \mathrm{~h}$ after $\mathrm{G} 2-\alpha-\mathrm{CD}^{\top}$ inhalation & $10.8 \pm 2.0$ & $1.3 \pm 0.4$ & $2.4 \pm 1.1$ \\
\hline $18 \mathrm{~h}$ after $\mathrm{G} 2-\alpha-\mathrm{CD}^{-}$inhalation & $12.9 \pm 2.0$ & $2.4 \pm 0.7$ & $3.2 \pm 1.1$ \\
\hline $24 \mathrm{~h}$ after $\mathrm{G} 2-\alpha-\mathrm{CD}$ inhalation & $6.4 \pm 0.4$ & $0.9 \pm 0.2$ & $1.1 \pm 0.3$ \\
\hline
\end{tabular}

BALF: bronchoalveolar lavage. ${ }^{\#}: \mathrm{n}=9-10{ }^{\top}:$ the exposed dose of $\mathrm{G} 2-\alpha-\mathrm{CD}$ was calculated as $334.6 \pm 2.2 \mu \mathrm{g} \cdot \mathrm{kg}^{-1}$ in the airways. *: $\mathrm{p}<0.05 ; * *: \mathrm{p}<0.01$ in comparison with the response of the untreated no ovalbumin (OA)-challenged group. 
either absorbed into the bloodstream or moved out of the lungs by cilia that are continually sweeping mucus up into the throat. In the search for and design of effective and safe drug formulations for the inhalation of CsA, the solubilising effect and cilio-inhibition may be the key issues. When an inhaled CsA is accumulated in the lung for the reasons of slow elimination from the lung lumen, regular usage may induce an adverse effect.

In the present study, DM- $\beta-C D$ was the best solubiliser of CsA of all the CDs examined, but it has severe cilio-inhibition potential. G2- $\alpha-C D$ showed relatively weak cilio-inhibition compared with the other CDs examined in this study. One of the most substantial requirements for drug carriers is that they have either no or acceptably low levels of intrinsic cytotoxicity. Studies with isolated erythrocytes, which have no nucleus, mitochondria, endoplasmic reticulum, or other organelles, may provide a simple and reliable measure to classify the CDs according to their cytotoxicity, because the interaction of CDs with plasma membranes must be the initial step of cell damage. The haemolytic activity of the natural CDs is reported to be in the order $\beta-\mathrm{CD}>\alpha-\mathrm{CD}>\gamma-\mathrm{CD}>\delta-\mathrm{CD}$ [21]. In the present study with pooled rabbit blood, $\alpha$-CD showed haemolytic activity at the same concentration range reported previously [21]. Under the experimental condition, G2- $\alpha-C D$ showed less haemolytic activity. Furthermore, ONO et al. [22] have suggested that $\mathrm{G} 2-\alpha-\mathrm{CD}$ has less cytotoxicity and less disturbing ability toward Caco-2 cell monolayers. In the authors' acute oral toxicity study, the acute lethal oral dose to rats of $\mathrm{G} 2-\alpha-C D$ was demonstrated to be $>2,000 \mathrm{mg} \cdot \mathrm{kg}^{-1}$ (data not shown). Thus, in view of safety properties which include weak cilio-inhibition and less cytotoxicity, and solubilising potency for CsA, G2- $\alpha-C D$ was a good candidate for the carrier of CsA in inhalation medicine. Furthermore, the cilio-inhibition potential of $\mathrm{G} 2-\alpha-\mathrm{CD}$ alone and $\mathrm{CsA}$ complexed with G2- $\alpha-C D$ was comparable to that of Intal Capsule $\mathbb{R}$, which was the commercially available dry powder product. Accordingly, CsA/G2- $\alpha-\mathrm{CD}$ were selected as the most suitable complex formulation for micronised dry powder inhalation of CsA.

Increasing numbers of eosinophils in the airways is a characteristic feature of asthma [4] and eosinophils are thought to play an important role in the pathogenesis of asthma by releasing a variety of mediators including toxic proteins [23]. Although the precise mechanisms of eosinophil accumulation are still uncertain, lymphocytes, especially T-helper cells that release interleukin- 4 and -5 , are considered to be key effector cells [24]. CsA inhibits eosinophil accumulation in the airways of rats [25] and guinea-pigs [26]. In the present study, CsA alone and CsA/G2- $\alpha-C D$ complex showed potent inhibitory effects on allergen-induced eosinophil influx into the airways of actively sensitised mice. CsA alone inhibited eosinophil influx into the airways of mice in a dose-dependent manner, and the utilised dose of CsA alone in this study was minimised to prevent this significantly (data not shown). Conversely, in the separated study using a rat asthmatic model, CsA/G2- $\alpha$ CD was $\sim 10$ times more effective on airway inflammation than CsA alone (data not shown). Indeed, the estimated inhaled dose of CsA contained in $\mathrm{CsA} / \mathrm{G} 2-\alpha-\mathrm{CD}$ complex was approximately nine-times less than that of CsA alone. From this point of view, in order to observe the same effect of CsA inhaled alone on the airway inflammation, the dose of CsA could be reduced by formation of an inclusion complex with G2- $\alpha-C D$. By this means, the toxic effect of CsA could be reduced.

In order to determine whether $\mathrm{G} 2-\alpha-\mathrm{CD}$ caused any effect on allergen-induced airway inflammation, the effect of G2- $\alpha$ $\mathrm{CD}$ inhaled alone was also examined. The estimated inhaled dose of G2- $\alpha-C D$ alone was approximately twice as high as that of $\mathrm{G} 2-\alpha-\mathrm{CD}$ contained in the $\mathrm{CsA} / \mathrm{G} 2-\alpha-\mathrm{CD}$ complex.
G2- $\alpha-C D$ inhaled alone did not show any effect on inflammatory cell accumulation in the airways. However, it should be noted that inhalation of G2- $\alpha-C D$ may have adverse effects on inflammatory cell influx, since the number of eosinophils rather tended to increase. Further studies are needed to determine the suitability of G2- $\alpha-C D$ for dry-powder inhalation in humans in terms of their local irritation potential. MARQUES et al. [10] have suggested that $\beta$-CDs could be absorbed after intratracheal instillation in rabbit. Although the authors did not observe the pharmacokinetics of CsA and G2- $\alpha-C D$ after the inhalation of the $\mathrm{CsA} / \mathrm{G} 2-\alpha-\mathrm{CD}$ complex, if $\mathrm{G} 2-\alpha-\mathrm{CD}$ could be absorbed to the circulation, possible induction of an antibody response should be considered for human use.

The rate and extent of absorption of a poorly water-soluble drug from its $\mathrm{CD}$ complex can be optimised by adjusting various factors that affect the dissociation equilibrium of the complex both in the formulation and in the biophase in which the complex is administered [5]. Only a free form of the drug, which is in equilibrium with the complex form of the drug in solution, is capable of penetrating lipophilic barriers consisting of either mucosal epithelia or stratified cell layers and eventually entering the systemic circulation [5]. Although the authors did not observe the interaction of CsA with G2- $\alpha-C D$ in aqueous solution, MIYAKE et al. [8] suggested that CsA interacts with DM- $\alpha-C D$ and DM- $\beta-C D$ in aqueous solution, and side chains of CsA may be involved. Therefore, the authors speculated that CsA interacted with $G 2-\alpha-C D$ in a similar way to DM-CDs. In the present study, the differences in onset and duration of action on eosinophil influx between CsA/G2- $\alpha-C D$ complex and CsA alone may be considered a consequence of the complex with G2- $\alpha-\mathrm{CD}$. The authors speculate that if the complex of CsA with G2- $\alpha-C D$ is relatively stable in the aqueous mucosal layer, then the dissolved CsA/ G2- $\alpha-C D$ complex persists at the absorption site and liberation of free CsA available for absorption would occur gradually in the site. Thus, further investigation of the dissociation equilibrium and stoichiometry of the $\mathrm{CsA} / \mathrm{G} 2-\alpha-\mathrm{CD}$ complex in both aqueous fluids and pharmaceutical formulations may be recommended.

In conclusion, the authors suggest that the effective dose of cyclosporin A for inhalation could be reduced by formulation of an inclusion complex with maltosyl- $\alpha$-cyclodextrin. Therefore, peripheral toxic effects of cyclosporin A, i.e. renal toxicity, could be attenuated via inhalation, leading to a wider therapeutic safety margin. Pharmacokinetics and toxicity of maltosyl- $\alpha$-cyclodextrin and cyclosporin $\mathrm{A} / \mathrm{maltosyl}-\alpha-$ cyclodextrin complex should also be determined further.

Acknowledgements. The authors would like to thank J. Fozard (Novartis AG, Basel, Switzerland) and M. Kometani (Novartis Pharma K.K., Tsukuba, Japan) for their helpful discussion and critical reading of the manuscript.

\section{References}

1. Nizankowska E, Soja J, Pinis G, et al. Treatment of steroiddependent bronchial asthma with cyclosporin. Eur Respir $J$ 1995; 8: 1091-1099.

2. Ceyhan BB, Sungur M, Celikel CA, Celikel T. Effect of inhaled cyclosporin on the rat airway: histologic and bronchoalveolar lavage assessment. Respiration 1998; 65: 71-78.

3. Klyashchitsky BA, Owen AJ. Nebulizer-compatible liquid formulations for aerosol pulmonary delivery of hydrophobic drugs: glucocorticoids and cyclosporin. J Drug Targeting 1999; 7: 79-99. 
4. De Monchy J, Kauffman HF, Venge P. Bronchoalveolar eosinophilia during allergen-induced late asthmatic reactions. Am Rev Respir Dis 1985; 464: 373-376.

5. Hirayama H, Uekama K. Cyclodextrin-based controlled drug release system. Adv Drug Deliv Rev 1999; 36: 125-141.

6. Sasamoto $\mathrm{Y}$, Hirose S, Ohno S, Onoe K, Matsuda H. Topical application of cyclosporin ophthalmic solution containing alpha cyclodextrin in experimental uveitis. Ophthalmologica 1991; 203: 118-125.

7. Hatanaka H, Komada F, Iwakawa S, Yamagami C, Okumura K. Effect of dimethyl- $\alpha$-cyclodextrin on the gastrointestinal absorption of cyclosporin. Jpn J Hosp Pharm 1995; 21: 295-301.

8. Miyake K, Hirayama F, Uekama K. Solubility and mass and nuclear magnetic resonance spectroscopic studies on interaction of cyclosporin A with dimethyl- $\alpha$ - and - $\beta$-cyclodextrins in aqueous solution. J Pharm Sci 1999; 88: 39-45.

9. Miyake K, Arima H, Irie T, Hirayama F, Uekama K. Enhanced absorption of cyclosporin A by complexation with dimethyl- $\beta$-cyclodextrin in bile duct-cannulated and noncannulated rats. Biol Pharm Bull 1999; 22: 66-72.

10. Marques HMC, Hadgraft J, Kellawat IW, Taylor G. Studies of cyclodextrin inclusion complexes. III. The pulmonary absorption of $\beta$-, DM- $\beta$ - and HP- $\beta$-cyclodextrins in rabbits. Int J Pharm 1991; 77: 297-302.

11. Srichana T, Suedee R, Reanmongkol W. Cyclodextrin as a potential drug carrier in salbutamol dry-powder aerosols: the in-vitro deposition and toxicity studies of the complexes. Respir Med 2001; 95: 513-519.

12. McMahon TA, Brain JD, Lemott S. Species differences in aerosol deposition. In: Walton WH, ed. Inhaled Particles IV. Part I. New York, Oxford University Press, 1977; pp. 23-32.

13. Gazeley MJS, Lees IW, Payne AN, Webbon PM, Woolley GE. Anatomical deposition and early distribution of an inhaled radioaerosol in conscious and anaesthetized rats. $\mathrm{Br}$ J Pharmacol 1986; 87: 122.

14. Puchelle E, Zahm JM, Sadoul P. Mucociliary frequency of frog palate epithelium. Am J Physiol 1982; 242: C31-C35.

15. Spungin B, Silberberg A. Stimulation of mucus secretion, ciliary activity, and transport in frog palate epithelium. $\mathrm{Am}$ J Physiol 1984; 247: C299-C308.
16. Di Benedetto G, Lopez-Vidriero MT, Carratu L, Clarke SW. Effect of amiloride on human bronchial ciliary activity in vitro. Respiration 1990; 57: 37-39.

17. Tomkiewicz RP, App EM, De Sanetis GT, et al. A comparison of a new mucolytic $N$-acetylcysteine L-lysinate with $N$-acetylcysteine: airway epithelial function and mucus change in dog. Pulm Pharmacol 1995; 8: 259-265.

18. Schipper NGM, Verhoef JC, Romeijin SG, Merkus FWHM. Methylated $\beta$-cyclodextrins are able to improve the nasal absorption of salmon calcitonin. Calcif Tissue Int 1995; 56: 280-282.

19. Schipper NGM, Romeijn SG, Verhoef JC, Merkus FWHM. Nasal insulin delivery with dimethyl- $\beta$-cyclodextrin as an absorption enhancer in rabbits: powder more effective than liquid formulations. Pharm Res 1993; 10: 682-686.

20. Merkus FWHM, Verhoef JC, Romeijn SG, Schipper NGM. Absorption enhancing effect of cyclodextrins on intranasally administered insulin in rats. Pharm Res 1991; 8: 588-592.

21. Miyazawa I, Ueda H, Nagase H, Endo T, Kobayashi S, Nagai T. Physicochemical properties and inclusion complex formation of $\delta$-cyclodextrin. Eur J Pharm Sci 1995; 3: 153162.

22. Ono M, Arima H, Hirayama F, Uekama K. A moderate interaction of maltosyl- $\alpha$-cyclodextrin with Caco- 2 cells in comparison with the parent cyclodextrin. Biol Pharm Bull 2001; 24: 395-402.

23. Barnes PJ. New concepts in the pathogenesis of bronchial hyperresponsiveness and asthma. J Allergy Clin Immunol 1989; 83: 1013-1026.

24. Robinson DS, Hamid Q, Ying S. Predominant TH2-like bronchoalveolar T-lymphocyte population in atopic asthma. N Engl J Med 1992; 326: 298-304.

25. Elwood W, Lotvall JO, Barnes PJ, Chung KF. Effect of dexamethasone and cyclosporin A on allergen-induced airway hyperresponsiveness and inflammatory cell responses in sensitized Brown-Norway rats. Am Rev Respir Dis 1992; 145: 1289-1294.

26. Norris AA, Jackson DM, Eady RP. Protective effects of cyclophosphamide, cyclosporin A and FK 506 against antigen-induced lung eosinophilia in guinea-pigs. Clin Exp Immunol 1992; 89: 347-350. 